\title{
Morphological and molecular identification and PCR amplification to determine the toxigenic potential of Fusarium spp. isolated from maize ears in southern Poland
}

\author{
Anna Monika Lenart • Agnieszka Klimek-Kopyra • \\ Piotr Mateusz Boroń
}

Received: 2 March 2012 /Accepted: 19 December 2012 /Published online: 4 January 2013

(C) The Author(s) 2013. This article is published with open access at Springerlink.com

\begin{abstract}
The average amount of precipitation in spring and summer 2010 and 2011 coupled with relatively high temperatures caused massive Fusarium spp. infection of maize and yield losses in southern Poland. In order to examine the cause of this disease outbreak, Fusarium spp. were isolated and fungal strains were identified based on morphological characters and species-specific PCR assays. A total of 200 maize samples were processed, resulting in the obtention of 71 strains, which belonged to five Fusarium species, F. poae being the predominant one $(74.56 \%)$. Other isolates were identified as $F$. graminearum, $F$. oxysporum, $F$. verticillioides and $F$. proliferatum. PCR-based detection of mycotoxinsynthesis-pathway genes was also used to determine the potential of the analyzed strains to produce trichothecenes (DON and NIV) and fumonisins (FUM).
\end{abstract}

\footnotetext{
A. M. Lenart $(\bowtie)$

Department of Microbiology,

University of Agriculture in Cracow,

30-059 Cracow, Poland

e-mail: annalenart82@gmail.com
}

\author{
A. Klimek-Kopyra \\ Department of Crop Production, \\ University of Agriculture in Cracow, \\ 31-120 Cracow, Poland \\ P. M. Boroń \\ Department of Forest Pathology, \\ University of Agriculture in Cracow, \\ 31-425 Cracow, Poland
}

Only 14 isolates revealed the potential to produce DON (11 strains) and FUM (3 strains). HPLC analyses of grain samples revealed the presence of DON only other mycotoxins were not detected. Moreover, 57.1\% of potentially mycotoxin-producing isolates indicated the toxicity in a biological test.

Keywords Mycotoxins - Species-specific PCR . Zea mays L.

\section{Introduction}

Maize (Zea mays L.) has high yield potential and a high content of nutrients, which plays a significant role in animal and human nutrition (Michalski 1999). This makes it a species of great economic importance. Together with wheat and rice it occupies a worldwide leading position in the production of food and animal feed. Maize accounts for $20 \%$ of the overall global area planted with cereals, accounting for $30 \%$ of global grain production. Currently, the traditional corn grain usage system prevails in Poland: nearly $80 \%$ of the harvest is used as feed (Statistical Yearbook of Agriculture 2010).

Maize plants are attacked by various pathogens such as Fusarium spp., Ustilago maydis, Sprisorium reiliana (Xu et al. 1999). One of the most commonly and widely studied maize diseases in Poland is Fusarium ear rot (Chełkowski et al. 1994, 2007; 
Pascale et al. 2002), which is a major threat to maize production worldwide, mainly due to the mycotoxinsproducing ability of Fusarium species. The Fusariummediated mycotoxin contamination is a potential health hazard for humans and animals consuming maize and maize-based products (Goertz et al. 2010). The growing period of 2008 was the first year when the hazard assessment of Fusarium spp. occurrence was monitored in Poland. Maize ear rot was reported commonly, but its severity was low (Statistical Yearbook of Agriculture 2010).

As the pathogenicity of various Fusarium species is diverse, the mycotoxin-production ability may vary even between particular strains (Goswami \& Kistler 2005). Rapid and accurate Fusarium spp. identification, as well as detection of their mycotoxin production ability, is therefore vital to reduce the harmful effects of the disease (Bayraktar \& Dolar 2011).

The amount of precipitation in southern Poland in spring and summer 2010 and 2011 was very high, the average rain amount exceeded significantly the monthly precipitation rates. Heavy rain coupled with relatively high average temperatures promoted growth of Fusarium spp. on cereals (Plaskowska 2010), which caused maize yield losses in 2010 and 2011.

The aims of this study were to (i) identify the Fusarium species isolated from maize ears in southern Poland in 2010 and 2011 using morphological and molecular methods by species-specific PCR; (ii) determine the genetic potential of Fusarium spp. isolates to produce nivalenol, deoxynivalenol and fumonisins; and (iii) evaluate the toxicity of metabolites of the maize-derived strains.

\section{Materials and methods}

Fungal isolates Maize grain samples were collected at the end of two growing seasons (October 2010 and 2011) from the experimental fields of University of Agriculture in Cracow located in Prusy, Małopolskie voivodeship (southern Poland). A total of 100 cobs of Zea mays were examined each year. Six maize seeds from each cob were surface-sterilized for 1 min with a $1 \%$ sodium hypochlorite solution $(\mathrm{NaOCl})$, rinsed twice in sterile distilled water and placed in petri dishes with Potato Dextrose Agar (PDA). The petri dishes were incubated for $5-7$ days at $25^{\circ} \mathrm{C}$. All Fusarium isolates were purified and stored at $4^{\circ} \mathrm{C}$ for further analyses. Morphological identification of Fusarium spp. was carried out according to Leslie \& Summerell (2006) and Nelson et al. (1983). The following characters of Fusarium cultures were assessed by eye and microscopic examination: colony morphology (PDA), macroconidia, microconidia and chlamydospores.

DNA extraction Fusarium spp. isolates were cultured on PDA for 7 days. Afterwards, mycelia were scraped into Eppendorf tubes with a sterile spatula. Total DNA was extracted from mycelium of each isolate (about $100 \mathrm{mg}$ wet weight) using Bead-Beat Micro Gravity DNA isolation kit (A\&A Biotechnology, Gdynia, Poland) according to the manufacturer's instructions. The isolation kit contained $1 \mathrm{~mm}$ Zirconia/Silica beads which enabled us to grind the mycelium using Retsch MM 400 Mixer Mill (30 Hz, $3 \mathrm{~min}$ ). The quality and quantity of DNA obtained was assessed using NanoDrop spectrophotometer (Thermo Scientific, USA).

Species-specific PCR Studied isolates were identified with species-specific PCR assay using previously published primer pairs for F. poae, F. oxysporum, F. graminearum, $F$. sporotrichioides, $F$. culmorum, $F$. proliferatum and F. verticillioides (Table 1). PCR reactions were performed for all isolates and sterile deionized water served as negative control. Positive control was not applied but all DNA templates gave eventually a product only with a single primer pair. The reaction mixtures of a total volume of $25 \mu$ contained $10 \times$ PCR buffer, $1.5 \mathrm{mM}$ of $\mathrm{MgCl}_{2}, 0.3 \mu \mathrm{M}$ of each primer, $0.2 \mathrm{mM}$ of dNTPs, $1 \mathrm{U}$ of Taq DNA Polymerase (Thermo Scientific - Fermentas, Canada) and approximately $25 \mathrm{ng}$ of fungal template DNA. PCR amplification was carried out in the Veriti 96Well Thermal Cycler (Applied Biosystems, Carlsbad, CA, USA) using temperature profiles described by Demeke et al. (2005), Koncz et al. (2008), Mishra et al. (2003), Mulè et al. (2004a) Nicholson et al. (1998), and Rahjoo et al. (2008). The PCR products were visualized by $1 \times \mathrm{TBE}$ electrophoresis in ethidiumbromide-stained $1 \%$ agarose gel.

Molecular analyses of the toxigenic potential of Fusarium spp. isolates The potential of Fusarium spp. isolates to produce fumonisin and trichothecenes was determined by the PCR-based molecular analyses 
Table 1 Species-specific primers used for the identification of Fusarium spp. isolated from maize plants

\begin{tabular}{|c|c|c|c|c|}
\hline Primer name & Sequence $5^{\prime}-3^{\prime}$ & Product size (bp) & Target fungi & Source \\
\hline $\begin{array}{l}\text { Fpo-R } \\
\text { Fsp-F }\end{array}$ & $\begin{array}{l}\text { CAGCGCACCCCTCAGAGC } \\
\text { CGCACGTATAGATGGACAAG }\end{array}$ & $\sim 400$ & $\begin{array}{l}\text { F. poae } \\
\text { F. poae, F. sporotrichioides }\end{array}$ & Jurado et al. 2005 \\
\hline Fsp-R & GTCAGAAGAGACGCATCCGCC & $\sim 400$ & F. sporotrichioides & Jurado et al. 2005 \\
\hline $\begin{array}{l}\text { Fgr-F } \\
\text { Fgc-R }\end{array}$ & $\begin{array}{l}\text { GTTGATGGGTAAAAGTGTG } \\
\text { CTCTCATATACCCTCCG }\end{array}$ & $\sim 500$ & F. graminearum & Jurado et al. 2005 \\
\hline $\begin{array}{l}\text { CLPRO1 } \\
\text { CLPRO2 }\end{array}$ & $\begin{array}{l}\text { TGCATCAGACCACTCAAATCCT } \\
\text { GCGAGACCGCCACTAGAT }\end{array}$ & 526 & F. proliferatum & Mulè et al. 2004a \\
\hline $\begin{array}{l}\text { VER1 } \\
\text { VER2 }\end{array}$ & $\begin{array}{l}\text { CTTCCTGCGATGTTTCTCC } \\
\text { AATTGGCCATTGGTATTATATATCTA }\end{array}$ & 578 & F. verticillioides & Mulè et al. 2004b \\
\hline $\begin{array}{l}\text { FOF1 } \\
\text { FOR1 }\end{array}$ & $\begin{array}{l}\text { ACATACCACTTGTTGCCTCG } \\
\text { CGCCAATCAATTTGAGGAACG }\end{array}$ & $\sim 340$ & F. oxysporum & Mishra et al. 2003 \\
\hline $\begin{array}{l}\mathrm{C} 51 \mathrm{~F} \\
\mathrm{C} 51 \mathrm{R}\end{array}$ & $\begin{array}{l}\text { ATGGTGAACTCGTCGTGGC } \\
\text { CCCTTCTTACGCCAATCTCG }\end{array}$ & $\sim 570$ & F. culmorum & Nicholson et al. 1998 \\
\hline
\end{tabular}

using the Tri13F and Tri13DONR, Tri13NIVF and Tri13R, and FUM1F and FUM1R specific primers pairs (Table 2) which target the mycotoxin-synthesispathway genes: Tri13DON (deoxynivalenol), Tri13NIV (nivalenol) and fum1 (fumonisin), respectively. PCR reactions were performed for all isolates and sterile deionized water served as negative control. Positive control was not used as the quality of all DNA extracts was assessed previously in species-specific PCR. The reaction mixtures of a total volume of $25 \mu$ contained $10 \times \mathrm{PCR}$ buffer, $2 \mathrm{mM}$ of $\mathrm{MgCl}_{2}$, $0.4 \mu \mathrm{M}$ of each primer, $0.2 \mathrm{mM}$ of dNTPs, $0.75 \mathrm{U}$ of Taq DNA Polymerase (Thermo Scientific - Fermentas, Burlington, Ontario, Canada) and approximately $50 \mathrm{ng}$ of fungal template DNA. PCR amplification was carried out in the Veriti 96-Well Thermal Cycler (Applied Biosystems) according to temperature profiles described by Lenc et al. (2008) and Yazeed et al. (2011). The PCR products were visualized by $1 \times \mathrm{TBE}$ electrophoresis in ethidium-bromide-stained, $1 \%$ agarose gel.
Biological tests In order to evaluate the phytotoxic effect of fungal metabolites to plants, the biological tests were performed with 14 Fusarium spp. isolates. Only potentially fumonisin- or trichotheceneproducing strains were included. The test was performed on 20 maize seeds per isolate according to the procedure described by Mirczink (1957). After incubation for 3, 5 and 10 days, percent germination energy was calculated for each isolate. Isolates were regarded as toxic when the germination energy was decreased by $30 \%$ or more as compared with control plants (Bis 2006).

Chemical detection of mycotoxins The studied maize grain samples, from which the potentially mycotoxinproducing Fusarium strains were isolated, were analyzed chemically to determine the concentration of deoxynivalenol, nivalenol and B1 and B2 fumonisins. Detection of mycotoxins was carried out at the National Veterinary Research Institute in Pulawy,

Table 2 Primers used for detection of the Fusarium spp. potential to produce trichothecenes and fumonisin

\begin{tabular}{lllll}
\hline Primer name & Sequence 5'-3' & Product size (bp) & Target sequence & Source \\
\hline FUM1 F & CCATCACAGTGGGACACAGT & 183 & fuml gene & Bluhm et al. 2004 \\
FUM1 R & CGTATCGTCAGCATGATGTA & & Tril3DON gene & Chandler et al. 2003 \\
Tri13F & CATCATGAGACTTGTKCRAGTTTGGG & 282 & Tril3NIV gene & Chandler et al. 2003 \\
Tri13DONR & GCTAGATCGATTGTTGCATTGAG & 312 & & \\
$\begin{array}{l}\text { Tri13NIVF } \\
\text { Tri13R }\end{array}$ & CCAAATCCGAAAACCGCA & & &
\end{tabular}


Poland, with high performance liquid chromatography (HPLC) assay, following the method described by Plattner (1999).

\section{Results}

Morphological and molecular identification A total of 71 strains (27 from the first year of the study) belonging to five Fusarium species were isolated from the analyzed maize grain samples. Based on morphological observations, 53 isolates were identified as $F$. poae, ten as $F$. graminearum, five as $F$. oxysporum and two as $F$. proliferatum. Five isolates, however, could not be identified to species level.

Because of incomplete morphological identification, the species-specific PCR analysis with all fungal isolates was performed. The species affiliation of all previously identified strains was confirmed. This method allowed also for identification of the isolates whose species could not be determined using morphological identification only. The expected amplicon sizes were obtained in PCR reactions for $F$. graminearum, $F$. oxysporum, $F$. poae, $F$. proliferatum and $F$. verticillioides (Fig. 1), whereas no isolate was identified as $F$. culmorum or $F$. sporotrichioides. The frequency of species occurrence is presented in Table 3.

Molecular analyses of the toxigenic potential of Fusarium spp. isolates Molecular detection of deoxynivalenol resulted in positive identification of 11 potential DON producers: seven isolates from the first year of the study (five $F$. poae strains, one $F$. graminearum strain and one $F$. proliferatum) and four isolates from the second year (two $F$. poae and two F. graminearum isolates). For those isolates the characteristic $282 \mathrm{bp}$-long fragment was

Fig. 1 PCR detection of various Fusarium species using species-specific primer sets: a Fsp-F/Fpo-R; b Fgr-F/Fgc-R; c FOF1/FOR1; d VER1/2; e CLPRO1/2. Lane 1: GeneRuler $1 \mathrm{~kb}$ DNA Ladder (ThermoScientific - Fermentas, Canada). Lanes A 2, 3, 4, 5, 6, 7: positively identified Fusarium poae isolates. Lanes B 2, 3, 4, 7: positively identified Fusarium oxysporum isolates. Lanes C 2, 3, 4, 5, 6, 7: positively identified Fusarium graminearum isolates. Lane D 4: positively identified Fusarium verticillioides isolate. Lanes E 3, 6: positively identified Fusarium proliferatum isolates
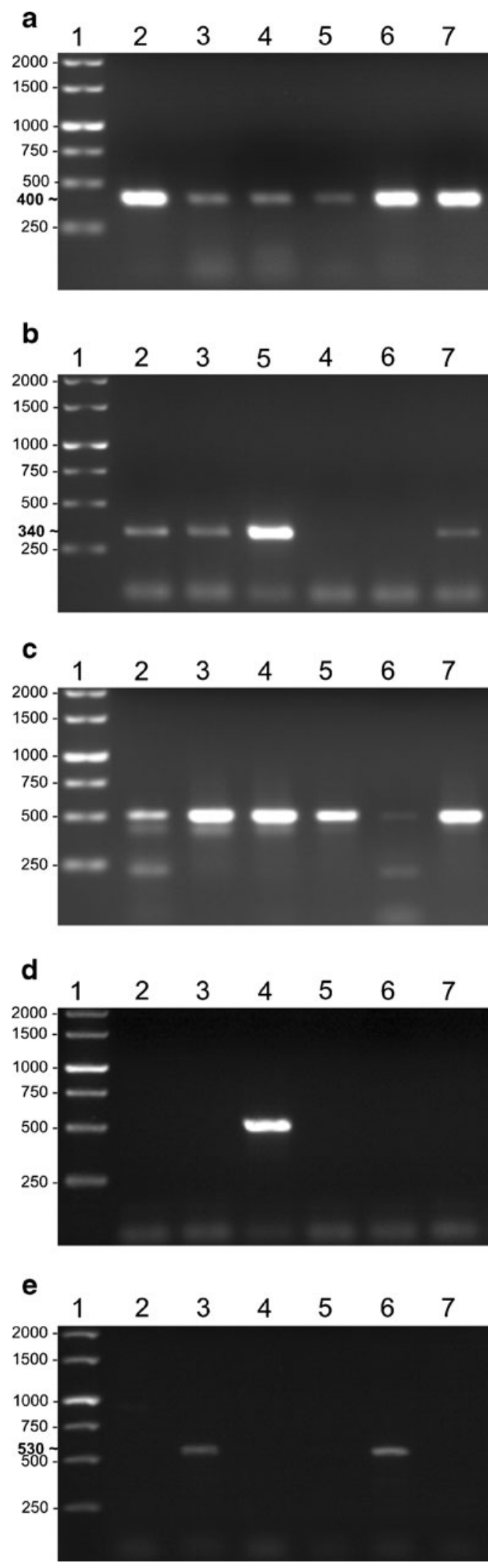
Table 3 Overall frequencies and percentage of various Fusarium species isolated from maize seeds in Prusy, southern Poland. Frequencies and percentage of potentially toxigenic (DON and FUM) isolates

\begin{tabular}{|c|c|c|c|c|}
\hline \multirow[t]{3}{*}{ Fungal species } & \multicolumn{4}{|l|}{ Year } \\
\hline & \multicolumn{2}{|l|}{2010} & \multicolumn{2}{|l|}{2011} \\
\hline & $\begin{array}{l}\text { No. of isolates } \\
\text { (percentage) }\end{array}$ & $\begin{array}{l}\text { No. of potentially toxigenic } \\
\text { isolates (percentage) }\end{array}$ & $\begin{array}{l}\text { No. of isolates } \\
\text { (percentage) }\end{array}$ & $\begin{array}{l}\text { No. of potentially toxigenic } \\
\text { isolates (percentage) }\end{array}$ \\
\hline F. poae & $21(29.57)$ & $6(8.45)$ & $32(45.07)$ & $2(2.82)$ \\
\hline F. graminearum & $3(4.23)$ & $1(1.41)$ & $7(9.86)$ & $2(2.82)$ \\
\hline F. oxysporum & $0(0)$ & $0(0)$ & $5(7.04)$ & $0(0)$ \\
\hline F. verticillioides & $1(1.41)$ & $1(1.41)$ & $0(0)$ & $0(0)$ \\
\hline F. proliferatum & $2(2.82)$ & $2(2.82)$ & $0(0)$ & $0(0)$ \\
\hline Total number/percentage of isolates & $27(38.03)$ & $10(14.08)$ & $44(61.97)$ & $4(5.63)$ \\
\hline
\end{tabular}

generated (Fig. 2a). Detection of the second trichothecene, nivalenol, gave no positive results, as the
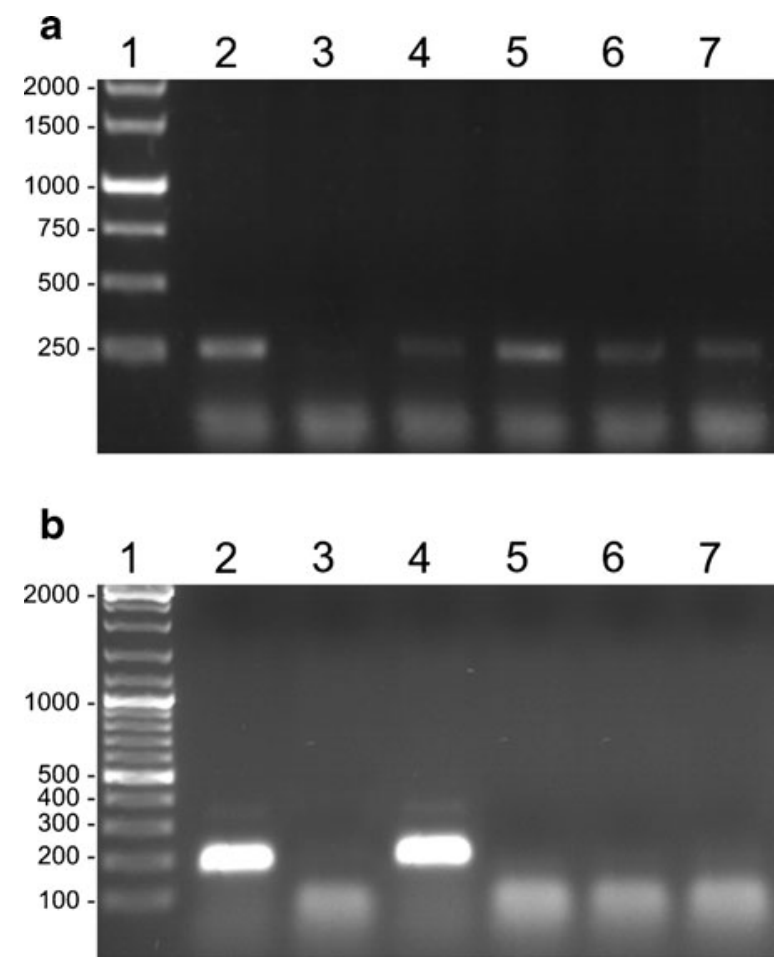

Fig. 2 PCR detection of DON and fumonisin production potential indicated by the presence of Tri13DON and fum 1 markers: a Tri13F/Tri13DONR; b FUM1 F/FUM1 R. Lane 1: a GeneRuler 1 kb DNA Ladder; b GeneRuler DNA Ladder Mix, 100-10,000 bp Ladder (ThermoScientific - Fermentas, Canada). Lanes A 2, 4, 5, 6, 7: positively identified presence of Tri13DON marker. Lanes B 2, 4: positively identified presence of fum1 marker expected product (312 bp) was not amplified for any of the studied isolates.

Detection of potential fumonisin producers was positive for three Fusarium spp. isolates from the first year of the study (one $F$. verticillioides, one $F$. poae and one $F$. proliferatum strain) only; the amplification yielded the expected product (size 183 bp) (Fig. 2b). No successful amplification was observed among Fusarium spp. strains obtained in 2011.

Frequencies and percentage of potential mycotoxin producing strains are given in Table 3.

Biological tests Biological tests were performed in order to determine whether fungal metabolites of 14 strains, whose mycotoxin-synthesis potential was revealed by the described PCR methods, exhibit toxicity to germinating maize seeds. Among the tested strains, metabolites of eight (57.1\%) turned out to be toxic, while the inhibiting effect of six of them (42.9\%) did not reach the $30 \%$ threshold (Table 4). The inhibition of germination energy caused by the studied Fusarium spp. strains ranged from $10 \%$ to $65 \%$.

Chemical detection of mycotoxins The HPLC analysis of maize grain samples showed varied deoxynivalenol concentration, oscillating around $1,000 \mu \mathrm{g} \times \mathrm{kg}^{-1}$. The concentration of DON ranged from 1,327 to $1,055 \mu \mathrm{g}$ $\times \mathrm{kg}^{-1}$. Only one sample contained a lower amount of DON $-694 \mu \mathrm{g} \times \mathrm{kg}^{-1}$. The other analyzed mycotoxins (nivalenol, fumonisin B1 and B2) were not detected. 
Table 4 The results obtained after 10 days of biological tests performed on 14 potentially mycotoxin-producing Fusarium spp. strains

\begin{tabular}{|c|c|c|c|}
\hline $\begin{array}{l}\text { Number } \\
\text { of a strain } \\
\text { (mycotoxin } \\
\text { potential) }\end{array}$ & Species & $\begin{array}{l}\text { No. of germinated } \\
\text { seeds per } 20 \\
\text { [inhibited } \\
\text { germination }(\%)]\end{array}$ & $\begin{array}{l}\text { Toxic }[+] / \\
\text { non-toxic } \\
{[-]}\end{array}$ \\
\hline 1 (FUM) & F. verticillioides & $11[45]$ & + \\
\hline 2 (FUM) & F. poae & $9[55]$ & + \\
\hline 3 (FUM) & F. proliferatum & $18[10]$ & - \\
\hline $4(\mathrm{DON})$ & F. poae & $19[5]$ & - \\
\hline $5(\mathrm{DON})$ & F. graminearum & $10[50]$ & - \\
\hline $6(\mathrm{DON})$ & F. poae & $16[20]$ & - \\
\hline 7 (DON) & F. poae & 18 [10] & - \\
\hline $8(\mathrm{DON})$ & F. graminearum & $11[45]$ & + \\
\hline $9(\mathrm{DON})$ & F. poae & 15 [25] & - \\
\hline $10(\mathrm{DON})$ & F. poae & 13 [35] & + \\
\hline $11(\mathrm{DON})$ & F. poae & $7[65]$ & + \\
\hline $12(\mathrm{DON})$ & F. proliferatum & 18 [10] & - \\
\hline $13(\mathrm{DON})$ & F. graminearum & $11[45]$ & + \\
\hline $14(\mathrm{DON})$ & F. poae & $12[40]$ & + \\
\hline C-0 & control & 20 & - \\
\hline
\end{tabular}

\section{Discussion}

This research was undertaken mainly to identify the cause of recently observed maize fusariosis in southern Poland, which was probably affected by increased rainfall rates in spring and summer of 2010 and 2011. Fusarium species-related diseases are important factors that decrease maize yields (Czembor et al. 2010); their significance is greater, since they may affect human or animal health due to mycotoxin synthesis ability (Goertz et al. 2010). Mycotoxin synthesis potential may, however, vary between strains, irrespective of the species (Goswami \& Kistler 2005). Knowledge of the species composition and, what is more important, mycotoxin synthesis potential of various Fusarium spp. strains, is therefore needed to estimate the risk of food and feed mycotoxin contamination.

The results obtained in this study indicated that $F$. poae was one of the most frequently isolated species (74.64\%), confirming other reports that this species is one of the most often isolated Fusarium spp. pathogens, not only in Poland, but also in other countries (e.g. Argentina, Austria, Canada, England, Germany,
Hungary, Ireland, Slovakia, Switzerland and Wales) (Stenglein 2009). Such a wide F. poae occurrence is unfavorable, as this species belongs to the causal agents of Fusarium ear rot (Chełkowski et al. 2007), which is one of the most important maize diseasesdecreasing yield and affecting grain quality and feed value of the grain (Czembor et al. 2010; Rahjoo et al. 2008).

Haratian et al. (2008) applied the positive-negative PCR assay based on the Tri13 gene to identify the genetic potential of DON and NIV production of $F$. graminearum. In this study, only 11 Fusarium spp. were found to be potentially deoxynivalenolproducing strains, as they gave positive amplification of 282 bp product with Tri13F and Tri13DONR primers. This indicates relatively rare deoxynivalenol production potential: $15.5 \%$ of all analyzed isolates. This is, however, much more than was detected in similar studies performed in Poland by Lenc et al. (2008), who did not find Fusarium spp. strains with the potential to produce DON. On the other hand, Burlakoti et al. (2008) in their TRI-based PCR assays, revealed that all studied strains had the DON marker.

The potential to synthesize the second trichothecene, viz., nivalenol was not detected; the NIVspecific Tri13 primers Tri13NIVF and Tri13R did not amplify the expected $312 \mathrm{bp}$-long product (which would have indicated the nivalenol-synthesis ability) among the studied Fusarium isolates. Similar results were reported by Pasquali et al. (2010), who did not find the potential NIV-producers among $F$. poae isolates derived from wheat harvested in Luxembourg. In other species detected by these authors, the NIV chemotype was also sporadically detected (representing only $5.8 \%$ of the total population). Haratian et al. (2008) revealed that both DON and NIV Fusarium spp. chemotypes existed in Iran, but NIV producers were more frequently reported.

The synthesis ability of the third considered mycotoxin, viz., fumonisin among Fusarium spp. isolates was analyzed in accordance with the PCR-based approach with FUM1-F and FUM1-R primer pair introduced by Sreenivasa et al. (2008). In this study, only three potential fumonisin producers could be identified. This result is surprising, as it is in contradiction with the data of Sreenivasa et al. (2008) and Yazeed et al. (2011), in which 53 of 64 plant-derived isolates and all of the 21 feed-samples-derived isolates, respectively, were identified as fumonisin producers. 
The results of the biological test are similar to the ones obtained by Bis (2006) in the analysis of potentially toxicogenic fungal strains isolated from soils in Cracow and its surroundings, where only $60 \%$ of the isolated strains could have been considered as toxic. Fusarium graminearum isolated from soil near a cement plant in Cracow appeared to be the most phytotoxic strain in that study. This strain caused $70 \%$ inhibition of germination energy of the tested plant seeds.

The last part of the study included the HPLC detection of deoxynivalenol, nivalenol and fumonisins. Out of three analyzed mycotoxins, only deoxynivalenol was detected. Nonetheless, the amounts of DON do not exceed the maximum levels according to the EC Regulation No. 1126/2007 L 255/14 regarding deoxynivalenol concentration in unprocessed maize. The results obtained from the chemical analyses confirm the results of the PCR amplification with primers targeting deoxynivalenol-synthesis-pathway genes, as several Fusarium spp. strains revealed the potential to produce this mycotoxin. Fumonisin contamination of grain samples has not been confirmed in HPLC detection, although three strains were identified as potential fumonisin producers in the PCR approach, and metabolites of two of them have proven to have an inhibiting effect on germinating maize seeds. These results are consistent with those obtained by Wang et al. (2010), who indicated in their study of Fusarium spp. isolated from asparagus that, although Fusarium spp. isolates containing FUM genes produced fumonisins in cultures, no fumonisin contamination was detected in the analyzed asparagus samples. This may be explained by the fact that although the isolates have the genetic potential to produce mycotoxins, the actual production of these secondary metabolites is a very complex process and may be affected by a number of factors, particularly by environmental conditions, e.g. temperature, oxygen tension, but also by $\mathrm{pH}$ of a medium, in which the fungus grows (Miller 2001).

The results obtained in this study indicate that the recent disease outbreak in maize crops in spring and summer of 2010 was caused mostly by Fusarium poae, although other species could also be isolated. A similar situation was observed in 2011, when this species was also the most frequently detected. Still, the mycotoxin-synthesis potential was relatively rare among the isolated strains. Moreover, mycotoxin contamination of grain samples, or inhibiting effect on germinating seeds, has not been observed in all of the potentially toxigenic strains. This means that toxin synthesis, even if possible, is triggered by additional external or internal factors. An interesting factor is that the results of the HPLC analysis and biological tests are not fully congruent, as fumonisin has not been detected in grain samples from which were isolated two potential fumonisin producers with an inhibiting effect on germinating seeds. This indicates that in vitro culturing may affect mycotoxin synthesis which would not have been produced in vivo, or that the concentration of the potential fumonisin producers would not have reached the detection threshold.

Acknowledgments This research was supported by grant No. 4102 funded by the Faculty of Agriculture and Economics, University of Agriculture in Cracow.

Open Access This article is distributed under the terms of the Creative Commons Attribution License which permits any use, distribution, and reproduction in any medium, provided the original author(s) and the source are credited.

\section{References}

Bayraktar, H., \& Dolar, F. S. (2011). Molecular identification and genetic diversity of Fusarium species associated with onion fields in Turkey. Journal of Phytopathology, 159, 28-34.

Bis, H. (2006). Ability to produce mycotoxins by fungi isolated from soils in Cracow and the surroundings. Scientific Journal of Wroctaw University of Environmental and Life Sciences - Agriculture, 546, 43-50.

Bluhm, B. M., Cousin, M. A., \& Woloshuk, C. P. (2004). Multiplex real-time PCR detection of fumonisin producing and trichothecene producing groups of Fusarium species. Journal of Food Protection, 3, 536-543.

Burlakoti, R. R., Ali, S., Secor, G. A., Neate, S. M., McMullen, M. P., \& Adhikari, T. B. (2008). Comparative mycotoxin profiles of Gibberella zeae populations from barley, wheat, potatoes and sugar beets. Applied and Environmental Microbiology, 74, 6513-6520.

Chandler, E. A., Simpson, D. R., Thomsett, M. A., \& Nicholson, P. (2003). Development of PCR assays to Tri7and Tri 13 trichothecene biosynthetic genes, and characterisation of chemotypes of Fusarium graminearum, Fusarium culmorum and Fusarium cerealis. Physiological and Molecular Plant Pathology, 62, 355-367.

Chełkowski, J., Lew, H., \& Pettersson, H. (1994). Fusarium poae (Peck) Wollenw. - Occurrence in maize ears, nivalenol production and mycotoxin accumulation in cobs. Mycotoxin Research, 10, 116-120.

Chełkowski, J., Ritieni, A., Wiśniewska, H., Mulè, G., \& Logrieco, A. (2007). Occurrence of toxic hexadepsipeptides 
in preharvest maize ear rot infected by Fusarium poae in Poland. Journal of Phytopathology, 155, 8-12.

Commission Regulation (EC) No. 1126/2007 (2007). Amending Regulation (EC) No. 1881/2006 setting maximum levels for certain contaminants in foodstuff as regards Fusarium toxins in maize and maize products, L 255/14.

Czembor, E., Adamczyk, J., Posta, K., István, S., Oldenburg, E., \& Schürch, S. (2010). Prevention of ear rots due to Fusarium spp. on maize and mycotoxin accumulation. ENDURE Maize Case Study - Guide Number 3.

Demeke, T., Clearm, R. M., Partick, S. K., \& Gaba, D. (2005). Species-specific PCR-based assays for the identification of Fusarium species and a comparison with the whole seed agar plate method and trichothecene analysis. International Journal of Food Microbiology, 103, 271-284.

Goertz, A., Zuehlkem, S., Spiteller, M., Steiner, U., Dehne, H. W., Waalwijk, C., et al. (2010). Fusarium species and mycotoxin profiles on commercial maize hybrids in Germany. European Journal of Plant Pathology, 128, 101-111.

Goswami, R. S., \& Kistler, H. C. (2005). Pathogenicity and in planta mycotoxin accumulation among members of the Fusarium graminearum species complex on wheat and rice. Phytopathology, 95, 1397-1404.

Haratian, M., Sharifnabi, B., Alizadeh, A., \& Safaie, N. (2008). PCR analysis of the Tri13 gene to determine the genetic potential of Fusarium graminearum isolates from Iran to produce nivalenol and deoxynivalenol. Mycopathologia, 166, 109-116.

Jurado, M., Vázquez, C., Patiño, B., \& González-Jaén, M. T. (2005). PCR detection assays for the trichothecene-producing species Fusarium graminearum, Fusarium culmorum, Fusarium poae, Fusarium equiseti and Fusarium sporotrichioides. Systematic and Applied Microbiology, 28, 562-568.

Koncz, Z. S., Magyar, D., Naar, Z., Kiss, A., \& Szecsi, A. (2008). PCR-based assays for the identification of Fusarium spp. originating from wheat grain. Cereal Research Communications, 36, 631-636.

Lenc, L., Łukanowski, A., \& Sadowski, C. (2008). The use of PCR amplification in determining the toxigenic potential of Fusarium sambucinum and $F$. solani isolated from potato tubers with symptoms of dry rot. Phytopathologia Polonica, 48, 12-23.

Leslie, J. F., \& Summerell, A. B. (2006). The Fusarium laboratory manual. Ames, IA, USA: Blackwell Publishing Professional.

Michalski, T. (1999). The healthiness of spring cereals depending on sowing density. Progress in Plant Protection, 39, $759-762$.

Miller, J. D. (2001). Factors that affect the occurrence of fumonisin. Environmental Health Perspectives, 109, 321-324.

Mirczink, T. G. (1957). O gribach obustwliwajuszczich toksicznost diernowo podzolistnoj poczwy rozlicznoj stiepieni okulturiennosti. About mycotoxigenic fungi isolated from humus-podzolic soils of varying degrees of agricultural transformation [in Russian]. Mikrobiologia, 26, 78-86.

Mishra, P. K., Fox, R. T. V., \& Culham, A. (2003). Development of a PCR-based assay for rapid and reliable identification of pathogenic Fusaria. FEMS Microbiology Letters, 218, 329-332.
Mulè, G., Susca, A., Stea, G., \& Moretti, A. (2004a). Specific detection of the toxigenic species $F$. proliferatum and $F$. oxysporum from asparagus plants using primers based on calmodulin gene sequences. FEMS Microbiology Letters, 230, 235-240.

Mulè, G., Susca, A., Stea, G., \& Moretti, A. (2004b). A speciesspecific PCR assay based on the calmodulin partial gene for identification of Fusarium verticillioides, F. proliferatum and F. subglutinans. European Journal of Plant Pathology, 110, 495-502.

Nelson, P. E., Toussoun, T. A., \& Marasas, W. F. O. (1983). Fusarium species. An illustrated manual for identification. University Park, PA, USA: The Pennsylvania State University Press.

Nicholson, P., Simpson, D. R., Weston, G., Rezanoor, H. N., Lees, A. K., Parry, D. W., et al. (1998). Detection and quantification of Fusarium culmorum and Fusarium graminearum in cereals using PCR assays. Physiological and Molecular Plant Pathology, 53, 17-37.

Pascale, M., Visconti, A., \& Chełkowski, J. (2002). Ear rot susceptibility and mycotoxin contamination of maize hybrids inoculated with Fusarium species under field conditions. European Journal of Plant Pathology, 108, 645-651.

Pasquali, M., Giraud, F., Brochot, C., Cocco, E., Hoffman, L., \& Bohn, T. (2010). Genetic Fusarium chemotyping as a useful tool for predicting novalenol contamination in winter wheat. International Journal of Food Microbiology, 137, 246-253.

Pląskowska, E. (2010). Characteristics and taxonomy of Fusarium fungi. Mikologia Lekarska (Medical Mycology), 17, 172-176.

Plattner, R. D. (1999). HPLC/MS analysis of Fusarium mycotoxins, fumonisins and deoxynivalenol. Natural Toxins, 7, 365-370.

Rahjoo, V., Zad, J., Javan-Nikkhah, M., Mirzadi Gohari, A., Okhorvat, S. M., Bihamta, M. R., et al. (2008). Morphological and molecular identification of Fusarium isolated from maize ears in Iran. Journal of Plant Pathology, 90, 463-468.

Sreenivasa, M. Y., Dass, R. S., Charith Raj, A. P., \& Janardhana, G. R. (2008). PCR method for the detection of genus Fusarium and fumonisin-producing isolates from freshly harvested sorghum grains grown in Karnataka, India. Journal of Food Safety, 28, 236-247.

Statistical Yearbook of Agriculture. (2010). Warsaw, Poland: Central Statistical Office.

Stenglein, S. A. (2009). Fusarium poae: a pathogen that needs more attention. Journal of Plant Pathology, 91, 25-36.

Wang, J., Wang, X., Zhou, Y., Du, L., \& Wang, Q. (2010). Fumonisin detection and analysis of potential fumonisinproducing Fusarium spp. in asparagus (Asparagus officinalis L.) in Zhejiang province of China. Journal of the Science of Food and Agriculture, 90, 836-842.

Xu, M. L., Melchinger, A. E., \& Lübberstedt, T. (1999). Speciesspecific detection of the maize pathogens Sporisorium reiliana and Ustilago maydis by dot blot hybridization and PCRbased assays. Plant Pathology, 83, 390-395.

Yazeed, H. A. E., Hassan, A., Moghaieb, R. E. A., Hamed, M., \& Refai, M. (2011). Molecular detection of fumonisin-producing Fusarium species in animal feeds using polymerase chain reaction (PCR). Journal of Applied Sciences Research, 7, 420- 427. 